Marquette University

e-Publications@Marquette

Exercise Science Faculty Research and

Publications

Exercise Science, Department of

8-2018

\title{
Background and Method of the Striving to be Strong Study a RCT Testing the Efficacy of a M-health Self-management Intervention
}

\author{
Polly Ryan \\ University of Wisconsin - Milwaukee \\ Paula E. Papanek \\ Marquette University, paula.papanek@marquette.edu \\ Mary Ellen Csuka \\ Medical College of Wisconsin \\ Melissa E. Brown \\ University of Wisconsin - Milwaukee \\ Sarah Hopkins \\ University of Wisconsin - Milwaukee
}

See next page for additional authors

Follow this and additional works at: https://epublications.marquette.edu/exsci_fac

\section{Recommended Citation}

Ryan, Polly; Papanek, Paula E.; Csuka, Mary Ellen; Brown, Melissa E.; Hopkins, Sarah; Lynch, Shelly; Scheer, Victoria; Schlidt, Andrea; Yan, Ke; Simpson, Pippa Margaret; Hoffman, Ray; and The Striving to be Strong Team, "Background and Method of the Striving to be Strong Study a RCT Testing the Efficacy of a Mhealth Self-management Intervention" (2018). Exercise Science Faculty Research and Publications. 164. https://epublications.marquette.edu/exsci_fac/164 


\section{Authors}

Polly Ryan, Paula E. Papanek, Mary Ellen Csuka, Melissa E. Brown, Sarah Hopkins, Shelly Lynch, Victoria Scheer, Andrea Schlidt, Ke Yan, Pippa Margaret Simpson, Ray Hoffman, and The Striving to be Strong Team 
Marquette University

e-Publications@Marquette

\section{Exercise Science Faculty Research and Publications/College of Health} Sciences

This paper is NOT THE PUBLISHED VERSION; but the author's final, peer-reviewed manuscript. The published version may be accessed by following the link in the citation below.

Contemporary Clinical Trials, Vol. 71, No. x (August 2018): 80-87. DOI. This article is (C) Elsevier and permission has been granted for this version to appear in e-Publications@Marquette. Elsevier does not grant permission for this article to be further copied/distributed or hosted elsewhere without the express permission from Elsevier.

\section{Background and Method of the Striving to be Strong Study a RCT Testing the Efficacy of a $M$-health Self-management Intervention}

Polly Ryan

University of Wisconsin-Madison, School of Nursing

Paula Papanek

Marquette University

Mary Ellen Csuka

Medical College of Wisconsin

Melissa E. Brown

University of Wisconsin Milwaukee

Sarah Hopkins

University of Wisconsin Milwaukee

Shelly Lynch

University of Wisconsin Milwaukee

Victoria Scheer

University of Wisconsin Milwaukee 


\author{
Andrea Schlidt \\ University of Wisconsin Milwaukee \\ Ke Yan \\ Medical College of Wisconsin \\ Pippa Simpson \\ Medical College of Wisconsin \\ Ray Hoffman \\ Medical College of Wisconsin \\ The Striving to be Strong Team
}

\title{
Abstract
}

\section{Background}

Osteoporosis is a prevalent and debilitating condition affecting $>50 \%$ of post-menopausal women. Yet, a low percentage of women regularly engage in health promoting behaviors associated with osteoporosis prevention. Complex, multidimensional, $\mathrm{m}$-Health interventions hold promise to effect engagement in health behavior change related to calcium and vitamin D intake, balance, core and leg strength, and physical activity.

\section{Methods}

Striving to be Strong study (R01NR013913-01) tests the efficacy of a research and theory based, patient centered, dynamically tailored intervention delivered via smart phone apps. Ecological Momentary Assessments (EMAs) enhance immediate feedback and complement traditional measures. The desired outcomes are the maintenance of osteoporosis self-management behaviors and a decrease in the loss of bone density over time. The Individual and Family Self-management Theory provided the conceptual foundation for the study. The sample consists of 290 healthy women between the ages of 40 and 60 with an anticipated attrition of 33\%. This three group repeated measures Randomized Clinical Trial spans a 12-month time period. Data collected occurs via web site, smart-phone app, self-report, observation, and measures. Proximal (engagement in osteoporosis health behaviors) and distal (serum vitamin D, DXA, and body composition) outcomes are collected for testing of the efficacy of the intervention and theory evaluation.

\section{Discussion}

Active and rigorous quality management processes continually evaluate enrollment and retention goals, functionality of the automated intervention delivery and data collection systems, EMAs, and dispersion of incentives.

\section{Introduction and background}

In the U.S., over 35 million women either have or are at high risk for an osteoporotic fracture at an anticipated cost of greater than $\$ 25.3$ billion by $2025[1,2]$. Osteoporosis is a disease affecting 1 out of 2 postmenopausal women [3], is rapidly growing among populations of color [[4], [5], [6], [7]], and causes high chronic disease burden worldwide $[\underline{5}, \underline{8}, \underline{9}]$.

Osteoporosis is under evaluated, diagnosed, and treated in all women [10]. While a great deal remains to be learned about bone health, there is international agreement that, in addition to genetics, bone health is related to nutrition, engagement in weight bearing vigorous activity, appropriate and timely monitoring, and for some 
individuals' use of pharmacological agents $[\underline{11}, 12]$. Yet only $6 \%$ of women have an adequate nutritional intake and exercise during menopausal transition, the time of greatest bone loss in women [[13], [14], [15], [16], [17]]. Failure to engage in recommended health behaviors is a pervasive public health problem negatively impacting a diverse number of outcomes; including the health of individuals [18], ability of health care systems to achieve condition specific outcomes, service use, cost of healthcare [4], and intervention fidelity in clinical trials [[19], [20], [21], [22]]. The vast disparity between the high prevalence of osteoporosis and the low number of women who engage in preventative care highlights this condition as one of many striking examples of the crucial role behavior change could play in improving health and decreasing health care costs [23].

New approaches to help people initiate and maintain the self-management of health behaviors are needed. Integration of the findings of health behavior change research suggests that engagement in self-management programs, self-regulation activities, social facilitation, collaborative goal setting, meaningful and regular feedback, and person-centered approaches used in complex multi-dimensional interventions delivered over time provide the potential to enhance long-term health behavior change $[15,24,25]$. Through technological advances health behavior change processes are being integrated into everyday activities via smart phone applications (Apps) - one type of m-health [[26], [27], [28], [29]]. Approximately $30 \%$ of app users purchase commercially developed health related apps. These apps are interesting, attractive, generally have good usability, and are profitable. However, data suggests these apps are purchased but are rarely used regularly over time [26]. For most commercially developed health apps the efficacy to change health behavior has not been systematically or rigorously tested $[\underline{29}, \underline{30}]$.

Osteoporosis is a prevalent and debilitating condition. A low percentage of women regularly engage in the behaviors related to bone health. Complex multidimensional interventions hold promise to effect engagement in health behavior change as people are drawn to technology to manage many aspects of life including health care. The aim of this article is to describe the methods used in the Striving to be Strong study (STBS) (R01NR013913-01), a study designed to test the impact of a theory and research based, person-centered, intervention delivered via smartphone app on health behaviors related to bone density, calcium intake, balance, strength, and physical activity.

\section{Study design}

\subsection{Aim, study design and hypotheses}

The goal of the study is to test the efficacy a theory based, patient centered, dynamically tailored intervention delivered via a cell phone app. The expected outcomes of STBS are achievement of an increase in women's initiation and long-term maintenance of osteoporosis self-management behaviors and stabilization of bone mineral density.

The objective of this paper is to describe the methods and procedures used in the STBS study [31]. STBS is a repeated measure, three group, randomized clinical trial (RCT) designed to test the efficacy of three approaches to the self-management of health behaviors associated with the prevention of osteoporosis in healthy middle age women. Health behaviors included dietary calcium and vitamin D intake, balance, core and leg strength, and frequency and intensity of physical activity. Testing of three self-management approaches included (a) an innovative, evidence and theory based, person centered, dynamically tailored app, (b) a comprehensive, standardized educational e-book, and (c) a usual care personally directed approach. Intervention delivery, data collection, and study management required participants to use a smart phone (iPhone). Women were able to use their own phone or were provided a phone for the duration of the study. Electronically delivered Ecological Momentary Assessments (EMAs) enhanced immediate feedback and 
complement traditional measures of health behaviors [32]. The desired outcomes included proximal and distal outcomes including engagement in self-management behaviors and the resultant decrease in the loss of bone density over time and maintenance or improvement in serum vitamin D levels.

The study specific hypotheses focused on testing the efficacy of the newly developed intervention, evaluating moderators and mediators of engagement in health behaviors, describing the processes of health behavior change, and evaluating the utility of the theoretical framework. Individual hypothesis and research questions are listed on Table 1.

Table 1. Research aims, hypothesis and research questions, and planned analysis.

\begin{tabular}{|c|c|}
\hline Aim, hypothesis, research questions & Planned analysis \\
\hline \multicolumn{2}{|l|}{$\begin{array}{l}\text { Aim A. Test the efficacy of Striving to be Strong, a } \\
\text { theory based, patient centered, dynamically tailored } \\
\text { intervention delivered via a cell phone app. }\end{array}$} \\
\hline $\begin{array}{l}\text { Hypothesis 1. Women participating in Striving to be } \\
\text { Strong will achieve higher levels of initiation and } \\
\text { maintenance of osteoporosis health behaviors when } \\
\text { compared with women using Boning Up and a Wait- } \\
\text { List control group as evaluated with self-report, } \\
\text { behavioral performance, and bio-behavioral } \\
\text { measures. }\end{array}$ & $\begin{array}{l}\text { Changes over time between and within groups will be } \\
\text { evaluated using a linear mixed models (LMM) for the } \\
\text { normally distributed data and GLMMs (generalized linear } \\
\text { mixed models) for non-normal data (potentially the } \\
\text { balance test data or the 6-minute Walk Test) or data } \\
\text { from scales that could have floor and ceiling effects. } \\
\text { Since some of the results for the scales will depend on } \\
\text { the distributional assumptions, validation of these } \\
\text { parametric results will use permutation based tests - } \\
\text { which make fewer assumptions, but may be less } \\
\text { powerful than parametric tests. }\end{array}$ \\
\hline \multicolumn{2}{|l|}{$\begin{array}{l}\text { Hypothesis 2. Women participating in Striving to be } \\
\text { Strong will have more positive health outcomes than } \\
\text { women given Boning Up or the Wait-List control group. }\end{array}$} \\
\hline \multicolumn{2}{|l|}{$\begin{array}{l}\text { Research Question 1: Based on data obtained from } \\
\text { participants in the Wait-List control group, to what } \\
\text { extent does "participant preference" affect choice and } \\
\text { use of the interventions? }\end{array}$} \\
\hline \multicolumn{2}{|l|}{$\begin{array}{l}\text { Aim B. Evaluate moderators and mediators of long- } \\
\text { term engagement in health behaviors. }\end{array}$} \\
\hline $\begin{array}{l}\text { Hypothesis 3: Literacy and level of patient activation } \\
\text { will moderate the impact of the intervention. }\end{array}$ & $\begin{array}{l}\text { Examination of the effects of the moderating variables on } \\
\text { the intervention will be tested with the interaction } \\
\text { between the intervention (over time) and the } \\
\text { moderating variables in the analytic models from Aim A. } \\
\text { The potential mediating variable effects on engagement } \\
\text { and long-term maintenance will be tested by comparing } \\
\text { direct effect and indirect effect models. Since these } \\
\text { models are not hierarchical, AIC and BIC criteria will be } \\
\text { used rather than likelihood tests. }\end{array}$ \\
\hline $\begin{array}{l}\text { Hypothesis 4: Health beliefs, self-regulation skills and } \\
\text { abilities, and social facilitation will mediate } \\
\text { engagement and long-term maintenance of health } \\
\text { behaviors. }\end{array}$ & \\
\hline
\end{tabular}




\begin{tabular}{|l|l|}
\hline $\begin{array}{l}\text { Aim C. Describe processes of health behavior change } \\
\text { and evaluate differences within and between subjects } \\
\text { with findings from EMAs. }\end{array}$ & \\
\hline $\begin{array}{l}\text { Research Question 2: Are there differences in } \\
\text { behaviors within and between participants in Striving } \\
\text { to be Strong, Boning Up, and Wait-List groups for } \\
\text { calcium, exercise/activity and balance during the } \\
\text { baseline, intervention and post-intervention periods? }\end{array}$ & $\begin{array}{l}\text { Overall comparisons will use the models of AIM A; } \\
\text { comparisons in behavior at the individual time points will } \\
\text { use Bonferroni multiple comparisons adjustment } \\
\text { together with the global model estimates for variances. } \\
\text { The Bonferroni adjustment applies both to GLMMs and } \\
\text { LMMs and is no more conservative than Tukey's HSD in a } \\
\text { 3 group ANOVA. }\end{array}$ \\
\hline $\begin{array}{l}\text { Aim D. Evaluate the utility of The Individual and Family } \\
\text { Self-Management Theory }\end{array}$ & $\begin{array}{l}\text { Research Question 3: What are the relative } \\
\text { contributions of knowledge and beliefs, self- } \\
\text { regulation skills and abilities, and social facilitation on } \\
\text { health behaviors and bone density and what are the } \\
\text { directions and strength of relationships among the } \\
\text { concepts within the context of osteoporosis } \\
\text { prevention? }\end{array}$ \\
$\begin{array}{l}\text { Family Self-management Theory will use specific models } \\
\text { based on the theory together with goodness of fit tests } \\
\text { to check for deviations from the model. Since the model } \\
\text { is multi-level, a hierarchical approach will be used to } \\
\text { evaluate consistency of the individual coefficients with } \\
\text { the contributions of knowledge and beliefs, self- } \\
\text { regulation skills/abilities and social facilitation on the } \\
\text { outcomes. }\end{array}$ \\
\hline
\end{tabular}

\subsection{Research findings inform study design and methods}

Historically, the most commonly used intervention to increase women's health behaviors to prevent and manage osteoporosis has been "health education" delivered via small group session. In preparation for designing the STBS study and making decisions impacting study methods Ryan and colleagues [38] conducted an integrated review of the literature to determine the impact of osteoporosis prevention programs on the health behavior of calcium intake. Twenty-nine studies were identified and 12 met the inclusion criteria for an experimental or quasi-experimental design. The results of this integrated review informed the methods of the study including the areas of eligibility, design, measures, attrition, and mode of intervention delivery.

\subsubsection{Research findings influencing eligibility}

In the systematic review described in the previous paragraph [38] three findings affected eligibility criteria for the STBS study. First, eligibility criteria affected the power to detect differences between groups. Studies including persons already engaging in the behavior being studied required a larger sample than studies excluding persons already achieving the recommended level of the behavior. Persons already engaging in a health behavior as recommended (e.g., already consuming the recommended amount of calcium in their diet) are not likely nor should they change their calcium intake. Applied to the STBS study, persons consuming recommended amounts of dietary calcium or regularly engaging in vigorous physical activity were not eligible to participate in the study.

Second, women who were informed they had osteoporosis responded more positively to interventions than women who had no knowledge of their bone density; hence becoming aware that one has the diagnosis of osteoporosis confounds study results and should be an exclusion criteria for this prevention study. Third, as there is a relationship between bone density and menopausal status, information about menopausal status becomes important to understanding study results. Applied to the STBS study information about menopausal status, symptoms of menopausal transition, and use of hormone replacement therapy was obtained. 


\subsubsection{Research finding influencing the design}

Differences between groups were more likely to be detected when a usual care group was included in the design. The STBS design included three groups or arms; the newly developed dynamically tailored app, the educational e-book, or usual care. Findings from the integrated review provided valuable evidence to support the need for and resources required to conduct a three-group study.

\subsubsection{Research findings influencing measurement}

The studies included in the integrated review used calcium intake and bone mineral density as screening tools, dimensions of the intervention, and outcome measures. In the STBS study results from the baseline bone density measures were used to both screen participants for eligibility and as a baseline measure used to detect differences among groups. Similarly, calcium intake was used as a screening tool, enabled women to monitor their daily calcium intake via the app, and a measure of calcium intake as across all measurement periods.

The tools used to measure calcium intake varied across the studies ranging from a general report of eating habits over the past year to in-depth food diaries with data recorded over multiple days. Comprehensive, multiple-day, real time food diaries had high participant burden, frequent errors related to non-specific documentation (e.g., brands and recipe ingredients), and required expensive and complex software to obtain desired information. Evidence from several of these studies supported the use of three-day "calcium focused" food diaries. The three-day diary was sensitive to change and appeared to be more accurately completed by women than comprehensive food diaries. In prior studies [31], this research team had used comprehensive food diaries but finding from this integrated review spurred researchers to further evaluate a simpler, but sensitive measures of change, calcium focused three-day food diary.

\subsubsection{Research finding related to attrition}

Not all studies included in the integrated review reported attrition. When reported, mean attrition averaged $33 \%$, ranging from no attrition to $42 \%$. Attrition was higher for control than experimental groups. Findings from this integrated review highlighted the need for the STBS study to have a comprehensive retention plan [32].

\subsubsection{Research finding related to power}

Successful interventions (defined as significant differences between groups) had medium to large effect sizes and tended to be complex (including multiple dimensions including information, skill training, and social contact). Longer interventions tended to be more successful than shorter interventions. The attrition rates observed in this integrative review, along with effect sizes of the interventions, were used to power the STBS study.

\subsubsection{Research findings related to technology}

There were no technology-based interventions in the literature at the time these articles were reviewed. This finding was identified as an opportunity to test technology as a media of delivery. STBS utilized cell phone apps and web-site technology.

\subsection{Sample}

In previous osteoporosis prevention studies, moderate effect sizes were obtained for interventions targeting calcium and exercise and attrition rates approximated 33\% [33]. It was determined 288 women needed to be enrolled to the STBS study for a final sample of 192 to attain a power of $80 \%$ and an alpha level of 0.01 (to make a multiple testing adjustment for the key outcomes). A 0.6 SD difference would correspond, for example, to a difference of $0.06 \mathrm{~g} / \mathrm{cm} 2$ in bone mineral density, $96 \mathrm{mg}$ in dietary calcium consumption, or 1.0 seconds on a timed balance test. 


\subsection{Individual and Family Self-Management Theory}

STBS was based on and provides data to further evaluate the utility of the Individual and Family SelfManagement Theory (IFSMT); a mid-range theory that focuses on process to enhance the self-management of health behavior change $[\underline{15}, \underline{24}, \underline{25}]$. The IFSMT purports that self-management of behavior change takes place in the context of risk and protective factors specific to the condition, physical and social environment, and individual and family. Health behavior change is a self-management process influenced by knowledge and health beliefs (self-efficacy and goal congruence), that uses active engagement in self-regulation skills and abilities (goal setting, self-monitoring, reflective thinking, decision making, planning, action, self-evaluation, and emotional control), and social facilitation (social influence, support, and collaboration with health care providers). Outcomes are proximal and distal - proximal outcomes focus on engagement in self-management behaviors; distal outcomes focus on changes in health and conditions.

\subsection{Study groups and apps}

STBS used mobile health ( $m$-health) media (iPhone and website) to deliver the intervention, collect measurement data, and provide a tool for communication between the participant and the study. All data were automatically recorded and stored in a HIPAA compliant cloud server.

Participants in Group 1 received the Striving app, a theory based, patient centered, dynamically tailored intervention designed to increase self-management behaviors delivered via smart phone app. The app contained current information and was based on existing evidence. The app was composed of five major sections including general information about osteoporosis and bone health and the four behavior sections related nutrition particularly dietary calcium and vitamin $\mathrm{D}$, balance, strength, and physical activity. The app was dynamic: adapting and modifying content in response to participants' repeated assessments and use over time. The (IFSMT) provided the theoretical structure that allowed for parallel construction of the four behavioral sections. The sub-sections for calcium, balance, strength, and physical activity were parallel focusing on information, assessments, personalized feedback, and activities designed to enhance self-regulation skills and abilities. Videos of recommended exercises matched the participants' ability and became progressively more or less demanding. Participants had the option to engage in structured or highly flexible self-regulation processes. Women were encouraged to use the app three to four times a week for 20 to 30 min per session. However, the individual controlled their actual use of the app (frequency and duration). The app automatically recorded and saved time used in general and by section, results of personal assessments, and self-regulation activities and outcomes.

Group 2 received Boning Up, an informational intervention prepared by the National Osteoporosis Foundation (NOF). Boning Up was originally a 100-page booklet [34]. With permission of the NOF the format was changed to an e-book and delivered via a smart phone app. The content, diagrams, and charts remained identical to the original book. The NOF reviewed and approved the final copy prior to use.

Group 3 was a Wait-List control group culminating with the participant choice to use, for their last 3-months, either the Striving or Boning Up app [[35], [36], [37], [38], [39]]. Like the other two groups, participants in Group 3 used the smart phone for personal use and all study activities including reception of all communication, completion of measurement tools, and the automated delivery of the EMAs.

A third app was developed for EMAs and was used by all participants. The EMA queried participants about their use of self-regulation processes related to the four health behaviors. A total of 284 EMA messages were sent to each participant over 12 months via text message. The number of messages delivered per week was predetermined and the computer system was programed to randomly select the day of the week and time of day the messages were sent. Participants were able to set and adjust a $10 \mathrm{~h}$ time period to receive messages. Up to 
two reminders were sent for each scheduled message that the participant did not answer. Response required less than 1 min of a participant's time. Frequency of messaging changed over time. Additionally, participants could initiate completion of an EMA at any time.

\subsubsection{Delivery media}

Participants who owned an iPhone 5, 5s, or 6, had the option to use their personal phone, retain their phone number, and receive $\$ 50$ a month compensation. Women who did not own an iPhone were given a "study phone" and the study covered the cost of the phone plan. The study phone was a 5S iPhone. The study phone plan provided 200 min talk time and unlimited text and data. Upon successful completion of the study, phone ownership and choice of and responsibility for a new phone plan was transferred to the participant.

The study website had "two sides", one side for the participant and the other side for the researcher. The participant side was used for recruitment, access to study documents of interest to participants, and a "live"

section for completion of measures. The link to the electronic measures opened two weeks prior to the date the measures were to be completed. Participants received an automatically generated email indicating the measurement links were open and that measures were ready for completion. Once the participant completed the measures, the links were closed until the next measurement cycle.

The second side of the website provided the researcher with access to participant data via reports and data files including measure completion and actual responses, gift card incentives, and EMA use and responses. These data were live; hence, researchers could visualize all areas of participation and were able to assess the functionality of all automated components of the system.

Selection of variables and their measures match the dimensions of the IFSMT (context, process, and proximal and distal outcomes) and focus on the osteoporosis health prevention behaviors of nutrition (calcium and vitamin D), balance, strength, and physical activity. Concepts measured for the contextual dimension included socio-demographics including education, menopausal status, social status, health and computer literacy, confidence in finding and using electronic health information, and activation. Concepts measured for the process dimension included knowledge of osteoporosis and osteoporosis prevention, behavior specific selfefficacy (calcium intake and physical activity), goal congruence (calcium and physical activity), self-regulation, self-management, measures of actual engagement in self-regulation process (real-time measures of intervention use and self-report of self-regulation), and measures of social support and collaboration with one's health care provider. Measures of proximal outcomes include self-regulation of specific prevention behaviors via EMAs, 3day food diaries, self-report and researcher measures of physical activity, strength, balance, and functional movement screen. Measures of distal outcome include bone density via DXA, body composition, risk assessment of osteoporotic fracture, and serum Vitamin D. Specific and detailed information about all of the study measures and their relationship to the IFSM theory is available elsewhere [40].

\subsection{Procedure}

\subsubsection{Protection of human rights}

A research consortium representing the Institutional Review Boards (IRB) of the three academic institutions involved in the study conducted a preliminary review of the study and made the determination that the IRB from the primary investigators university was to be the IRB of record. Participant consent was obtained three times; specifically, Step 1 phone screening (participants deferred written consent), a written consent for Step 2 Dual-energy X-ray Absorptiometry (DXA) screening, and the third signed consent for enrollment in the study. In preparation for in-person appointments women received a written copy of the consents. At the appointment questions were encouraged and answered. A "teach back" technique was used to ensure that women understood their rights and the study procedures and requirements. Researchers used this appointment to 
evaluate the person's ability to read and understand written English - information important to obtaining an informed consent and an eligibility requirement. Two copies of the consent were signed. The study retained one copy and the participant was given the second copy.

\subsubsection{Eligibility and screening}

Eligibility was determined using a two-step screening process (see Fig. 1). Step 1 was a telephone interview conducted by experienced registered nurses with research experience. Eligibility criteria required women to be between the ages of 40 and 60, healthy, not pregnant or lactating. Healthy was defined as (a) a score of $<1$ on the Physical Activity Readiness Questionnaire [42], (b) not hospitalized in the past year for a chronic condition, (c) fewer than five visits to a health care provider for the same condition, (d) not receiving disability, (e) $>5$-years post active treatment for cancer (f) or not taking medications directly impacting bone. Volunteers were not eligible if they self-reported a diagnosis of osteoporosis or history as an adult of a fragile fracture (a fracture to an arm, leg, hip, or vertebra not associated with major trauma). Volunteers successfully completing step 1 screening advanced to step 2 , a DXA screening.

\begin{tabular}{|c|c|c|c|c|c|c|c|c|}
\hline & \multicolumn{8}{|c|}{ STUDY PERIOD } \\
\hline & \multirow{2}{*}{$\begin{array}{c}\begin{array}{c}\text { Enrolme } \\
\text { nt }\end{array} \\
-t_{l}\end{array}$} & \multirow{2}{*}{$\begin{array}{c}\begin{array}{c}\text { Allocati } \\
\text { on }\end{array} \\
\\
0\end{array}$} & \multicolumn{5}{|c|}{ Post-allocation } & \multirow{2}{*}{$\begin{array}{c}\text { Close-out } \\
\text { End of } \\
\text { Study } \\
\text { Appointme } \\
\text { nt } \\
\end{array}$} \\
\hline TIMEPOINT"** & & & $\begin{array}{c}\text { Baseli } \\
n e\end{array}$ & $T_{\text {smo }}$ & $T_{\text {tamo }}$ & $T_{9 m o}$ & $T_{12 \mathrm{mat}}$ & \\
\hline \multicolumn{9}{|l|}{ ENROLMENT: } \\
\hline $\begin{array}{r}\text { Eligibility screen: } \\
\text { Phase I }\end{array}$ & $\mathrm{x}$ & & & & & & & \\
\hline $\begin{array}{r}\text { Eligibility screen: } \\
\text { Phase II DXA }\end{array}$ & $\mathrm{x}$ & & & & & & & \\
\hline Informed consent & $\mathrm{x}$ & & & & & & & \\
\hline Allocation & & $\mathrm{X}$ & & & & & & \\
\hline \multicolumn{9}{|l|}{ INTERVENTIONS: } \\
\hline \multicolumn{9}{|l|}{ Striving to be Strong } \\
\hline \multicolumn{9}{|l|}{ Boning $U_{p}$} \\
\hline \multicolumn{9}{|l|}{ Personal Choice } \\
\hline \multicolumn{9}{|l|}{ ASSESSMENTS: } \\
\hline $\begin{array}{r}\text { DXA, TBS, BodyComp, } \\
\text { Serum Vitamin D }\end{array}$ & & $\mathrm{X}$ & & & & & & $\mathrm{X}$ \\
\hline \multirow{2}{*}{$\begin{array}{l}\text { Researcher collected } \\
\text { measures of physical } \\
\text { Functioning }\end{array}$} & & & $\mathrm{x}$ & & & & & $\mathrm{x}$ \\
\hline & & & $\mathrm{x}$ & $\mathrm{x}$ & $\mathrm{x}$ & $\mathrm{x}$ & $\mathrm{X}$ & \\
\hline Self-reported measures & & & $\mathrm{x}$ & $\mathrm{x}$ & $\mathrm{x}$ & $\mathrm{x}$ & $\mathrm{x}$ & \\
\hline \multicolumn{9}{|l|}{ EMA } \\
\hline \multicolumn{9}{|l|}{$\begin{array}{r}\text { App Use: Time, } \\
\text { Section, Assessment }\end{array}$} \\
\hline & & & & & & & & $\mathrm{x}$ \\
\hline End of Study Interview & & & & & & & & \\
\hline
\end{tabular}

Fig. 1. Schedule of enrolment, interventions, and assessments.*

*Recommended content displayed using schematic format as suggested by SPIRIT 2013 [43].

Preliminary data required for the standardization of the DXA scan were collected (height, weight, birth date, race and ethnicity). Height was measured without shoes using a wall-mounted stadiometer (calibrated upon installation). Weight was obtained in pounds and ounces via an electronic scale (Tanita BWB-800A, 3-point weight calibration twice yearly). Bone Mineral Density was obtained with the iDXA General Electric model (Madison, Wl; Software 14.10.002), calibrated prior to each testing day. An over the counter pregnancy test was done if a woman was not $100 \%$ confident she was not pregnant. Bone mineral density (BMD) was analyzed for total femur, femoral neck, and lumbar spine: L1-L4. Volunteers were not eligible for the study if they had a score below - 2.5 as determined by DXA. Ineligible volunteers were advised to contact their health care provider and a printed copy of the baseline DXA report was mailed to their provider. Eligible volunteers were scheduled for a 
second appointment or were enrolled in the study and completed their baseline measurements, assessments, and teaching immediately following the DXA scan.

\subsubsection{Random assignment and enrollment}

In compliance with University IRB policies, the PI and study's statistician developed a procedure for randomly assigning participants to treatment group. Prior to the start of the study 300 cards were prepared, 100 with the name of each study group. The card was placed in a sealed opaque envelope. A person unfamiliar with the study put all envelopes in a "bucket" and thoroughly mixed the envelopes. One at a time an envelope was pulled from the bucket and consecutively numbered from 1 to 300 . The numbered envelopes were stored in a locked drawer. At the baseline appointment, a member of the research team selected the next consecutive envelope from the drawer; logged the number, documented the day and time, and signed the log. The sealed envelope was given to the participant to open and she shared the information with the research team. At this appointment the participant shared her choice to use her own or a study iPhone.

Unblinding of the intervention group occurred during this baseline appointment, as it was necessary to provide the appropriate group-matched app-education and to deploy the correct app to woman's personal or a study phone.

\subsubsection{Participation requirements}

To remain in the study participants were required to complete a number of activities over the 12-months of their study. Everyone was to attend a baseline and end of study appointments for data collection including a DXA scan, physical measures of balance and strength, phone and app education and competency assessment, and end of study in-person interview. Women were to complete the electronic study measures at 3, 6, 9, and 12 months. Participants were to use one phone for their personal and study use. Participants were required to connect weekly with the study in one of several simple ways (e.g., logging into the app or completion of EMA). If using a study phone, women were required to limit phone use to the number of minutes provided by phone plan and not to use the phone outside mainland USA. Apps were to be retained on the phone for the duration of the study. Participants were asked to take reasonable care to prevent accidental damage to the phone. The study phone was to be returned if the participant chose to withdraw or was removed from the study. In addition, participants were asked not to disclose any information about their app with other study participants.

Before their first visit, participants were sent directions and were asked to compete baseline information electronically. At the baseline appointment, data and comfort with the use of the technology were reviewed and difficulties remedied. Participants were provided a secure login and connections to text messages, email, website, study app, and EMAs were tested. Participants watched two voice-over power points; one on iPhone use and the second on app use. Participants received printed copies of study contact information, the power point handouts from the previously viewed programs, schedules for data collection and EMAs, a copy of the signed consent, and a copy of body composition with directions for interpretation. The appropriate apps were wirelessly deployed to the participant's phone using Meraki software by Cisco.

In a structured and comprehensive, but personalized, teaching session the researcher and participant completed a list of skills and activities necessary to participate in the study. The baseline appointment was concluded when the researcher was confident of the participant's ability to use the phone and apps. Participants were encouraged to contact the study if they experienced any problems. Select members of the research team were available to provide technical assistance and answer questions. This assistance was available at least $50 \mathrm{~h}$ per week. 


\subsubsection{Data collection and procedural activities}

Data were collected in a number of ways. A telephone call was used for Step 1 screening. An in-person appointment was required for the collection of scans, blood, and physical measures at baseline and end of the study. All measures were acquired in the same sequential order at baseline and end of study. Breaks were built into the schedule to prevent fatigue and to maintain hydration. One of the physical activity measures, the Functional Movement Screen, was videotaped from a front and side perspective and later scored by certified reviewers. Self-report data were collected electronically at baseline, 3, 6, 9, and 12 months. And EMA data were collected on a random schedule throughout the 12-month study period.

In anticipation of the due date for completion of measures, reminder texts and email messages were sent using an automated reminder system. Completion of measures was automatically tracked. Failure to complete the measures in a timely basis triggered an automated email to the study. In the event of missing or incomplete measures researchers contacted the participant directly. All problems related to completion of measures were case managed.

At the end of the study women returned to the university for the second DXA, all physical measures were recollected, and an open-ended interview was conducted. Study apps were removed from phones. The research team transferred ownership of the phone to those participants using study phones. These women were given detailed directions on how to transfer the phone plans to their name. Women received a packet containing a printed copy of the results of baseline and end of study DXA scans and body composition. Included in the packet was an article explaining DXA scans and results. Information on how to interpret their personal results was included in this packet. Paper copies of DXA scans were mailed to the woman's designated health care provider.

\subsubsection{Retention}

A formal plan to retain participants for the duration of the 12 month study was used. This plan included a number of different incentives including transferring ownership of the iPhone to persons completing all the study requirements. Women using their own iPhone receive $\$ 50 /$ month to help cover the cost of their phone plan. Women received gift cards for completing the 3, 6, 9, and 12-month measures (amount increasing from $\$ 10$ to $\$ 30$ over time) and for responding to EMA messages (for a potential total of $\$ 40$ over 12 months). Participants receive personalized note cards containing token gifts of appreciation regularly throughout the study.

\subsubsection{Quality monitoring}

A quality management approach was used to manage the study procedures. Target goals were set, data collection forms and processes developed, and data regularly collected and reviewed. Decisions to adjust study procedures were based on data obtained from participants and members of the research team. Additional data related directly to the operational components of the study (e.g., recruitment and retention numbers) were collected and reviewed at a weekly team meeting. Matching the proposed time line to actual outcomes was critical to study management. Alterations to both app development (limiting the app development to an iPhone platform while excluding other smart phones) and the alternative recruitment plan occurred during the study (increasing the number of women recruited per month over a shorter time period).

\section{Analysis}

On a weekly basis all data were transferred from the website to the database used for analysis. Following each data collection period data were cleaned, missing data evaluated, and basic descriptive statistics run. Reliability coefficients were evaluated and reports including clean data were added to tables for interim and final report preparation. 
As described in the sample size section, an alpha level of 0.01 will adjust for the tests of the multiple key outcomes (see Table 1). Every effort will be made to avoid missing data, using all available sources. Using logistic regression (LR), the assumption of missing at random data will be explored. If the data appear missing at random (MAR) multiple imputations for items and, longitudinally, random effects models will be used.

Screening data are summarized as frequency counts and percentages. For comparison of the 3 groups, the Kruskal-Wallis test for continuous variables, and the Chi-square or Fisher's exact test for categorical variables will be used. Effectiveness of random assignment will be evaluated by comparing the three groups (Striving, Boning-Up, and Wait List) for all baseline measures using Statistical Analysis System, version 9.4. See Table 1 for planned analysis of specific research questions.

\section{Discussion: management challenges}

\subsection{IFSMT and app development}

The Striving app was a complex, multidimensional intervention. The app contained general information as well as information specific to nutrition, balance, strength, and physical activity. Usability required information to be organized and use the app to be intuitive for participants. The IFSMT was used as the overarching framework to provide the logic for app development. The four behavior sections were constructed using the same template. While this was intended primarily to help participants, researchers and members of the development team found using the theory to organize app content helpful. Once the theory was understood researchers assisting with writing, illustrating, and selecting photos used the theory as a blueprint to prepare the apps. Likewise, once the development team understood the theory and its components, code from one section could be adapted for use in other sections - saving significant amount of coding time.

\subsection{Managing by goals, timeline, and data}

During the first two years the team experienced a number of challenges to project management. The development of the apps and procurement of cell phones were delayed significantly. To manage this delay the protocol was adjusted and DXA screening and enrollment were changed from one to two appointments. Women were screened for eligibility and enrollment was delayed to a second appointment. Once the app was prepared and usability testing complete, previously screened eligible volunteers were enrolled at the same time new participants were recruited and screened. Having and regularly reviewing established time line and monthly target recruitment goals enabled the team to evaluate the relationship between the delay in app development activities and recruitment goals.

During screening appointments, researchers became aware of the strong impact of "word of mouth" on recruitment. Volunteers became the most effective source of recruitment as many of the women were told about the study by friends, relatives, and co-workers. Word of mouth recruitment, however, posed a potential threat to the internal validity of the study: specifically dissemination of innovation [41]. Sharing apps across groups could alter the treatment effect. The study managed this potential problem in several ways. With approval of the IRB changes were made to the consent and the process of obtaining consent was altered. A paragraph was added requesting participant not to share their app with other women in the study. Additionally, during the process of obtaining consent members of the research team discussed with each participant the reason for not sharing their app with other study participants. During the end of study interview, women were provided an opportunity to talk about sharing (or not) their app with other participants.

Balancing the rigor of an RCT with participant preferences demanded that procedures were both structured and flexible. Anticipating that the screening, enrollment and baseline assessments, data collection, and instructional sessions would take $6-8 \mathrm{~h}$, a number of potential schedules were developed. Participants could choose to come 
for one long session, two shorter session, or more and shorter sessions. Protocols were developed for each option ensuring that the order in which participant assessments and data completion tasks were done remained the same. Morning and afternoon appointments were scheduled on two different weekdays and one Saturday a month. Tracking and using study management data was used to determine women's appointment choices. Study data enabled us to understand our scheduling needs, resulted in an increase in our productivity, and allowed researchers to self-schedule; a practice that lead to higher satisfaction among the members of the research team.

\subsection{Technical issues}

In general, the apps worked well and few individuals experienced actual technical problems. Several exceptions occurred. For example one day all participants and researchers lost access to the study apps. The problem was identified and fixed rapidly, however all study apps needed to be re-installed. In preparation for the study members of the research and development team worked with an Apple engineer to identify and test software enabling wireless deployment of apps. As a result of the decision to use a wireless deployment system the apps were re-installed to all persons with minimal or no any loss of data in less than a week. Participants were not required to make an additional trip to the study site to fix the problem and most communication between the team and the participants could be managed on the website or with secure email.

Interventions delivered via technology will have technical problems and adding technical expertise to the team is an imperative. However, an ability to assess and solve problems along with clearly and simply communicating with team members and participant are imperative characteristics of all staff. Members of the research team rose to the management of the problem with incredible competence and skill while collaboratively solving problems. Many of our participants commented on the rapid and helpful information and the quick response to what they recognized as a potentially significant problem.

\section{Progress to date}

Two hundred women were recruited for this trial: data are being cleaned and prepared for analysis.

\section{Acknowledgements}

Research reported in this publication was supported by the National Institute of Nursing Research of the National Institutes of Health under Award Number R01NR013913. The content is solely the responsibility of the authors and does not necessarily represent the official views of the National Institutes of Health. The award was made to the University of Wisconsin-Milwaukee (UWM) while Dr. Ryan, PI, was a Research Associate at UWM College of Nursing with contributions by Board of Regents of the University of Wisconsin System on behalf of the University of Wisconsin-Milwaukee.

\section{Additional members of the Striving to be Strong Team}

Co-Investigator: Iqbal Ahamad, $\underline{P h D}$, Marquette University.

Consultant: Roger Brown PhD. University of Wisconsin Milwaukee.

Study Team: Sandra Lynn Danduran; Gina Scheidt, MD; Katalyn Skelton Stanaszak, MSN, RN, AGCNS-BC; Jenna Speltz, BS, MS:, Karen Wilson BSN, RN.

IT Team, Marquette University, College of Mathematics and Computer Science: Mel Bilen, BS; Duc Do, BS;

Taskina Fayezeeni, BA; ABM Kowser Patwary, BS.

Student Workers, Marquette University College of Health Science: Franceska Wenninger, Zachary Vandenberg, Kelsey Krushinsky, Margaret Smith. 


\section{References}

[1]National Osteoporosis Foundation Osteoporosis Fast Facts https:/cdn.nof.org/wpcontent/uploads/2015/12/Osteoporosis-Fast-Facts.pdf (2015), Accessed 3rd Sep 2017

[2] National Osteoporosis Foundation Fast Facts: Osteoporosis National Osteoporosis Foundation (2011)

[3] Z.A. Cole, E.M. Dennison, C. Cooper Osteoporosis epidemiology update Curr. Rheumatol. Rep., 10 (2) (2008), pp. $92-96$

[4] R. Burge, B. Dawson-Hughes, D.H. Solomon, J.B. Wong, A. King, A. Tosteson Incidence and economic burden of osteoporosis-related fractures in the United States, 2005-2025 J. Bone Miner. Res., 22 (3) (2007), pp. 465-475

[5] R.E. Cole Clinical strategies to address patients' concerns in osteoporosis management with bisphosphonates Postgrad. Med., 123 (2) (2011), pp. 131-144

[6]C. Holroyd, C. Cooper, E. Dennison Epidemiology of osteoporosis Best Pract. Res. Clin. Endocrinol. Metab., 22 (5) (2008), pp. 671-685

[7] L. SanchezRiera, N. Wilson, N. Kamalaraj, J.M. Nolla, C. Kok, Y. Li, M. Macara, R. Norman, J.S. Chen, E.U. S mith, P.N. Sambrook, C.S. Hernandez, A. Woolf, L. March Osteoporosis and fragility fractures Best Pract. Res. Clin. Endocrinol. Metab., 24 (6) (2010), pp. 793-810

[8] International Osteoporosis Foundation Facts and Statistics About Osteoporosis and Its Impact http://www.iofbonehealth.org/facts-and-statistics.html (2011), Accessed 11th Jan 2012

[9] O. Johnell, J.A. Kanis An estimate of the worldwide prevalence and disability associated with osteoporotic fractures Osteoporos. Int., 17 (12) (2006), pp. 1726-1733

[10] International Osteoporosis Foundation How Fragile is Her Future? https://www.iofbonehealth.org/howfragile-her-future (2000)

[11] F. Cosman, S.J. de Beur, M.S. LeBoff, E.M. Lewiecki, B. Tanner, S. Randall, R. Lindsay Clinician's Guide to Prevention of Osteoporosis: Position Paper vol. 25, Osteoporosis International (2014), pp. 2359-2381

[12]

M. Sattari, J.A. Cauley, C. Garvan, K.C. Johnson, M.J. Lamonte, W. Li, M. Limacher, T. Manini, G.E. Sarto, S .D. Sullivan, J. Wactawski-Wende, R.J. Beyth Osteoporosis in the women's health initiative: another treatment gap? Am. J. Med., 130 (2017), pp. 937-948

[13] E.O. Im, B. Lee, W. Chee, A. Stuifbergen, M.R.T.E Attitudes toward physical activity of white midlife women J. Obstet. Gynecol. Neonatal. Nurs., 40 (3) (2011), pp. 312-321

[14] R. Recker NOF President, Dr. Robert Recker, Delivered Remarks Friday, September 9 at the Joint Meeting of the FDA Reproductive Health Drugs and Drug Safety and Risk Management Advisory Committee http://www.nof.org/node/574 (2011), Accessed 11th Jan 2012

[15] P. Ryan Integrated Theory of Health Behavior Change: background and intervention development Clin. Nurse Spec., 23 (3) (2009), pp. 161-170 (quiz 171-172)

[16] P.F. Schnatz, K.A. Marakovits, M. Dubois, D.M. O'Sullivan Osteoporosis screening and treatment guidelines: are they being followed? Menopause (New York, N.Y.), 18 (10) (2011), pp. 1072-1078

[17]J. Wilbur, A. Vassalo, P. Chandler, J. McDevitt, A.M. Miller Midlife women's adherence to home-based walking during maintenance Nurs. Res., 54 (1) (2005), pp. 33-40

[18] C.A. Smith A systematic review of healthcare professional-led education for patients with osteoporosis or those at high risk for the disease Orthop. Nurs., 29 (2) (2010), pp. 119-132

[19] R.D. Gambrell Jr. The Women's Health Initiative reports in perspective: facts or fallacies? Climacteric, 7 (3) (2004), pp. 225-228

[20]

R.D. Jackson, A.Z. LaCroix, M. Gass, R.B. Wallace, J. Robbins, C.E. Lewis, T. Bassford, S.A. Beresford, H.R. Black, P. Blanchette, D.E. Bonds, R.L. Brunner, R.G. Brzyski, B. Caan, J.A. Cauley, R.T. Chlebowski, S.R. Cu mmings, I. Granek, J. Hays, G. Heiss, S.L. Hendrix, B.V. Howard, J. Hsia, F.A. Hubbell, K.C. Johnson, H. Jud d, J.M. Kotchen, L.H. Kuller, R.D. Langer, N.L. Lasser, M.C. Limacher, S. Ludlam, J.E. Manson, K.L. Margolis , J. McGowan, J.K. Ockene, M.J. O'Sullivan, L. Phillips, R.L. Prentice, G.E. Sarto, M.L. Stefanick, L. Van 
Horn, J. Wactawski-Wende, E. Whitlock, G.L. Anderson, A.R. Assaf, D. Baradl. Women's Health Initiative, Calcium plus vitamin D supplementation and the risk of fractures N. Engl. J.

Med., 354 (7) (2006), pp. 669-683

[21] W.H. Utian NIH and WHI: Time for a mea culpa and steps beyond Menopause (New York, N.Y.), 14 (6) (2007), pp. 1056-1059

[22] K. Ang, N. Hepgul, W. Gao, I.J. Higginson Strategies used in improving and assessing the level of reporting of implementation fidelity in randomised controlled trials of palliative care complex interventions: a systematic review Palliat. Med., 32 (2) (2017), 10.1177/0269216317717369

[23] K. Mckeown Empowering Patients as Key Decision Makers in the Face of Rising Health Care Costs, Backgrounder, (no. 2635) (2011) (pp. January 17, 2012)

[24] P. Ryan, K.J. Sawin The individual and family self-management theory: background and perspectives on context, process, and outcomes Nurs. Outlook, 57 (4) (2009) (217-225.e6)

[25] P. Ryan, K. Sawin Individual and Family Self-Management Theory (Revised Figure) http://www4.uwm.edu/nursing/about/centers-institute/self-management/theory/cfm (2014)

[26]C. Free, G. Phillips, L. Felix, L. Galli, V. Patel, P. Edwards The effectiveness of M-health technologies for improving health and health services: a systematic review protocol BMC Res. Notes, 3 (2010), p. 250

[27] T.L. Webb, J. Joseph, L. Yardley, S. Michie Using the Internet to promote health behavior change: a systematic review and meta-analysis of the impact of theoretical basis, use of behavior change techniques, and mode of delivery on efficacy J. Med. Internet Res., 12 (1) (2010), Article e4

[28] J. Slomian, J.Y. Reginster, U. Gaspard, S. Streel, C. Beaudart, G. Appelboom, F. Buckinx, O. Bruyere Exploring the interest in and the usage of the internet among patients eligible for osteoporosis screening Calcif Tissue Int., 96 (2015), pp. 518-526

[29] K. Patrick, E.B. Hekler, D. Estrin, D.C. Mohr, H. Riper, D. Crane, J. Godino, W.T. Riley The pace of technologic change: implications for digital health behavior intervention research Am. J. Prev. Med., 51 (5) (2016), pp. 816-824

[30] F. Modave, J. Bian, T. Leavitt, J. Bromwell, C. Harris, H. Vincent Low quality to free coaching apps with respect to the American College of Sports Medicine guidelines: a review of current mobile apps Jmir Mhealth Uhealth, 3 (3) (2015)

[31] P. Ryan, D. Maierle, M. Csuka, A. Thomson, A. Szabo Computer-based intervention to enhance selfmanagement of calcium and vitamin D intake in women West. J. Nurs. Res., 35 (8) (2013), pp. 986-1010

[32] S. Lynch, A. Schlidt, P. Ryan, Exemplar of an evidence based approach to recruitment and retention, (In preparation).

[33] P. Ryan, A. Schlidt, C. Ryan The impact of osteoporosis prevention programs on calcium intake: a systematic review Osteoporos. Int., 24 (2013), pp. 1791-1801, 10.1007/s00198-012-2259-4

[34] National Osteoporosis Foundation Boning Up on Osteoporosis: A Guide to Prevention and Treatment National 1002Osteoporosis Foundation, Washington, DC (2008)

[35] N.M. Clark, N.K. Janz, J.A. Dodge, L. Mosca, X. Lin, Q. Long, R.J. Little, J.R. Wheeler, S. Keteyian, J. Liang The effect of patient choice of intervention on health outcomes Contemp. Clin. Trials, 29 (5) (2008), pp. 679-686

[36] S.L. England, J. Evans Patients' choices and perceptions after an invitation to participate in treatment decisions Social Sci. Med., 34 (11) (1992), pp. 1217-1225

[37] M. King, I. Nazareth, F. Lampe, P. Bower, M. Chandler, M. Morou, B. Sibbald, R. Lai Impact of participant and physician intervention preferences on randomized trials: a systematic review JAMA, 293 (9) (2005), pp. 1089-1099

[38] K.J. Mccaffery, R. Turner, P. Macaskill, S.D. Walter, S.F. Chan, L. Irwig Determining the impact of informed choice: separating treatment effects from the effects of choice and selection in randomized trials Med. Decision Making, 31 (2) (2011), pp. 229-236

[39] P.E. Terry, E.L. Seaverson, M.J. Staufacker, S.B. Gingerich A comparison of the effectiveness of a telephone coaching program and a mail-based program Health Educ. Behav., 37 (6) (2010), pp. 895-912 
[40] P. Ryan, M. Weiss, P. Papanek A substruction approach to assessing the theoretical validity of measures J. Nursing Measure (2002)

[41]W.R. Shadish, T.D. Cook, D.T. Campbell Experimental and Quasi-Experimental Designs for Generalized Causal Inference, Boston (2002)

[42] Canadian Society for Exercise Physiology Physical Activity Readiness Questionnaire PARQ www.csep.ca (2015)

[43] A.W. Chan, J.M. Tetzlaff, D.G. Atman, A. Laupocis, P.C. Gotzsche, et al. SPIRIT 2013 statement: defining standard protocol items for clinical trials Ann. Intern. Med., 158 (3) (2013), pp. 200-207, 10.7326/0003$\underline{4819-158-3-201302050-00583}$ 